\title{
Time-Varying Taylor Rule Estimation for Turkey with Flexible Least Square Method
}

\author{
Barıș Soybilgen* \\ Istanbul Bilgi University
}

\author{
Burak Alparslan Eroğlu* \\ Istanbul Bilgi University
}

\begin{abstract}
In this study, we estimate a time-varying Taylor rule for evaluating the policy reaction function of the Central Bank of the Republic of Turkey (CBRT). Even though the Turkish economy has been continuously evolving in the last 15 years, previous studies that analyze the monetary policy rule of the CBRT mainly use time-invariant monetary policy functions. We propose a flexible two-stage least square regression to deal with both instability and endogeneity problems in the monetary policy functions. By analyzing the period between 2006 and 2019, we clearly show that the monetary policy function of the CBRT changes over time, and using a time-invariant monetary policy rule model would yield misleading results.
\end{abstract}

Keywords: Taylor Rule; Monetary Policy; Time-Varying Parameter; Turkey

JEL Classification: E52; E58; C32

\section{Esnek En Küçük Kareler Metodu ile Türkiye için Zaman İçinde Değişen Taylor Kuralı Kestirimi}

\section{Özet}

$\mathrm{Bu}$ çalışmada, Türkiye Cumhuriyet Merkez Bankası'nın (TCMB) politika fonksiyonunu zamanla değişen bir Taylor kuralı kullanarak değerlendirdik. Türkiye ekonomisi son 15 yılda sürekli değişmesine rağmen, önceki çalışmalar TCMB'nin para politikasını analiz etmek için zamanla değişmeyen para politikası fonksiyonları kullandıkları görülmektedir. Bu çalışmada para politikası fonksiyonlarındaki kararsızlık ve içsellik problemlerini çözen iki aşamalı esnek en küçük kareler regresyonu geliştirdik. Bu yöntemle 2006 ve 2019 yılları arasındaki periyodu incelediğimizde, TCMB'nin para politika fonksiyonun zaman içerisinde değiștiğini ve zamanla değişmeyen para politikası kuralı modellerinin doğru olmayan sonuçlar verebileceğini açıkça gösterdik.

Anahtar Sözcükler: Taylor Kurall; Para Politikası; Zamanla Değişen Parametre; Türkiye

JEL Sinıflandırması: E52; E58; C32

\footnotetext{
* Barış Soybilgen is an Assistant Professor in the Faculty of Business at Istanbul Bilgi University, Santral Istanbul, Kazim Karabekir Cad. No: 2/13, Eyup, Istanbul, Turkey. E-mail: baris.soybilgen@ bilgi.edu.tr.

*** Burak Alparslan Eroğlu is an Assistant Professor in the Faculty of Business at Istanbul Bilgi University, Santral Istanbul, Kazim Karabekir Cad. No: 2/13, Eyup, Istanbul, Turkey. E-mail: burak.eroglu@ bilgi.edu.tr.
} 


\section{Introduction}

After Turkey suffered from the years of high inflation and frequent economic recessions in the 90 s, Turkey started an ambitious economic restructuring plan at the beginning of the 2000s. As one of the first steps, Turkey switched to a flexible exchange rate from a crawling pegged exchange rate regime in 2001 and adopted an unofficial inflation targeting (hereafter, IT) regime in 2002. After improving the inflation outlook between 2002 and 2005, the Central Bank of the Republic of Turkey (hereafter, CBRT) officially adopted IT in 2006. After the abandonment of a fixed exchange rate regime (Brada and Kutan, 1999), a flexible exchange rate, and a monetary policy based on IT is deemed to be the only optimal policy mix for a country (Taylor, 2000). For monetary policy to be accepted as an IT, Kuttner (2004) states that a central bank needs to have at least an inflation target and a Taylor (1993) rule-based policy reaction function. Even though central banks usually reveal their inflation targets, researchers need to estimate their monetary policy rules. In this study, we propose a new approach to evaluate the CBRT's monetary policy function during the inflation targeting regime using a model that allows for coefficients of the monetary policy function to change over time.

In its basic form, the Taylor rule explains how central banks adjust the short-term interest rate by considering the output and inflation gaps. Many authors criticized the first interest ratebased monetary policy rule proposed by Taylor (1993) for not taking account of the lagged effect of monetary policy on the real economy. To remedy this problem, Clarida et al. (1998) propose a forward-looking version of the Taylor rule by using expectations of variables instead of the lagged of these variables. Additionally, their results reject the backward-looking Taylor rule in favor of the forward-looking rule for the United States, Germany, and Japan. For Turkey, utilizing a Vector Autoregressive (VAR) Analysis of the CBRT's monetary policy, Civcir and Akçağlayan (2010) show that the CBRT focuses on the forecasted inflation rate and disregards the impact of the lagged inflation rate. In another notable study, Aklan and Nargeleçekenler (2008) estimate both backward- and forward-looking monetary reaction functions. The authors also show that the response coefficients of the forward-looking Taylor rule models are higher than those of the backward-looking models. Similarly, Çiçek (2013) also compares the backward- and forward-looking Taylor rules and shows that the CBRT follows a forward-looking Taylor rule. Following the literature, we also estimate a forwardlooking monetary policy reaction function in this study.

There are already quite a few studies that estimate the forward-looking monetary policy reaction function of the CBRT since the implementation of the IT regime (e.g., Yazgan and Y1lmazkuday, 2007; Aklan and Nargeleçekenler, 2008; Gozgor, 2012; Güney, 2016). A notable drawback of these studies is that they disregard the possibility of parameter changes in the monetary policy function of the CBRT. However, the literature well documents that the monetary policy function of central banks usually changes over time (see, Yüksel et al., 2013). Therefore, it is crucial to model the time-varying nature of the policy function. For instance, Kayhan et al. (2013) use a two-state Markov switching model following the approach of King et al. (1996) to investigate the monetary policy function of the CBRT between 2002M02 and 2011M02. However, a simple two state Markov switching model is not flexible enough to capture the complete evaluation of the monetary policy conducted by the CBRT as Turkey faced many different economic phases during the last 15 years. To remedy this problem, Erdem et al. (2017) use the Kalman filter to extract the time-varying parameters of a forward-looking Taylor rule for Turkey but, they disregard the endogeneity problem of the forward-looking monetary policy rules. To resolve both the instability of the parameters and the endogeneity in the policy reaction functions like the Taylor rule, Soybilgen et al. (2019) use two-stage least 
squares (2SLS) with structural breaks. Soybilgen et al. (2019), who use the inflation gap, the output gap, and the first lag of the real rate as the explanatory variables, find that there are four different monetary policy periods in Turkey: 2002M03-2004M08, 2004M09-2008M11, 2008M12-2011M10, and 2011M11-2018M08. In their study, Soybilgen et al. (2019) clearly show that each period has different characteristics. Additionally, the authors claim that the studies that do not take into account the parameter instability would yield misguiding results.

In this study, we extend the framework outlined by Soybilgen et al. (2019) in two significant ways. First, we adopt a 2SLS with the flexible least squares (hereafter, FLS) instead of a 2SLS with the ordinary least squares and structural breaks, as the former procedure provides a more flexible and smooth evaluation of coefficients over time. Secondly, we add the real effective exchange rate (hereafter, REER) gap into our policy function in addition to the inflation gap, the output gap, the smoothing term, and the first lag of the real rate. Taylor (2001) argues that central banks should be indifferent to temporary exchange rate shocks when conducting monetary policy. However, exchange rate shocks are usually significant and permanent in emerging markets and may cause central banks to miss their inflation targets while reducing their credibility. As expected, Mohanty and Klau (2005) show that many central banks in emerging countries respond strongly to the fluctuations in the exchange rate. These exchange rate shocks also threaten the financial stability of the real economy by deteriorating the balance sheets of the companies, especially in the highly dollarized emerging markets like Turkey. Since the sub-prime mortgage crisis, the central banks of both developed and emerging countries increasingly take account of the financial stability when conducting their monetary policy. Kara (2016) also states that the CBRT modified the inflation targeting framework by incorporating financial stability as a supplementary objective after 2011. In one of the studies that analyze the effect of the exchange rate on the CBRT's monetary policy functions, Civcir and Akçağlayan (2010) show that the CBRT reacted strongly to the exchange rate shocks but weakly to output gap during the IT period. In another study that estimates Taylor rule type reaction functions, including exchange rates between 2003 and 2012, Gozgor (2012) finds that the CBRT responds significantly to exchange rate depreciation.

Our results show that the CBRT mostly considers the REER dynamics, especially during the rapid exchange rate depreciation. Furthermore, we show that the CBRT usually follows a counter-cyclical monetary policy function, even though the weight given to the output gap declines after the global financial crisis. The CBRT has also put increasingly more emphasis on the inflation gap since 2012. In a competing model, we also estimate a regular time-invariant Taylor rule equation. Our results indicate that fully comprehending the monetary policy of the CBRT is not possible without considering parameter instability. Finally, we show that the FLS method captures the changes in the monetary policy function of the CBRT better than the rolling window (hereafter, RW) least squares and recursive least squares (hereafter, RLS).

We organize the rest of the study as follows: In Section 2, we introduce a brief overview of the Turkish economy. In Section 3, we introduce our flexible 2SLS model. In section 4, we present our data. In Section 5, we demonstrate our empirical results, and we conclude in Section 6. We place all tables and figures in the Appendix.

\section{Brief Overview of the Turkish Economy}

In the 90s, Turkey had numerous economic problems such as the chronic budget deficit, sticky high inflation, frequent financial crises, and a weak banking sector. To overcome this problem, Turkey implemented several economic policies in the 2000s. First, Turkey switched to a flexible exchange rate regime from a pegged exchange rate regime in 2001. Then, the CBRT 
adopted a new monetary policy framework called the implicit IT regime in 2002. As the prerequired technical and macroeconomic conditions in Turkey did not satisfy the full-fledged IT regime yet, the CBRT chose not to adopt the IT regime formally (Kara, 2008). In 2006, The CBRT switched to explicit IT when the macroeconomic conditions in Turkey became more favorable.

We present six figures to analyze the macroeconomic and financial situation of Turkey during the IT period. Figure 1 shows the evolution of the inflation rate in Turkey between 2002M012005M12 and between 2006M01-2019M03. Figure 2 presents the annual inflation targets and the actual inflation rate between 2002 and 2019. Figure 3 shows the two-year benchmark interest rate and 12-months ahead inflation expectations and the real interest rate as the difference between them for 2002M01-2005M12 and 2006M01-2019M03. Figure 4 displays the official policy rate, weighted average funding rate, and the overnight TRLIBOR for the period of 2002M01-2005M12 and the period of 2006M01-2019M03. Figure 5 shows the real effective exchange rate and 12 months of the cumulative current account balance. Finally, Figure 6 presents the year-over-year industrial production index for Turkey.

The CBRT reduced the inflation rate from $70 \%$ to single-digit numbers under the implicit inflation targeting regime, as shown in Figures 1 and 3. A high real interest rate, which was more than $10 \%$ during this period, attracted large volumes of capital inflows and caused the Turkish Lira to appreciate sharply. At the same time, Turkey started to accumulate a sizeable current account deficit even though the Turkish economy has never experienced such a current account deficit historically. This policy mix caused the export sector of Turkey to deteriorate due to the overvalued Turkish Lira. However, this situation helped the CBRT to meet the inflation targets, as seen in Figure 2 during the implicit IT regime. The high and positive-valued real interest rates, overvalued Turkish Lira, and the high current account deficits continued until the sub-prime mortgage crisis. During the global crisis, the emerging markets, as well as Turkey, experienced large capital outflows and exchange rate shocks. Figures 5 and 6 clearly show that the current account deficit and industrial production of Turkey contracted sharply in 2008 and 2009. To revive the economy in this period, the CBRT lowered interest rates drastically.

Even though the Turkish interest rates were not as high as the pre-crisis period, Turkey, like the other emerging countries experienced large capital inflows due to the vast monetary expansion conducted by the central banks of developed countries after the global financial crisis. In 2010 and 2011, the Turkish Lira appreciated quickly, and the current account deficit reached unprecedented levels. At the end of 2011, it was evident that the large account deficit was unsustainable, and the sudden stop risk for Turkey was increasing rapidly. As a result, the CBRT adopted a non-orthodox monetary policy by curbing credit expansion while maintaining low policy rates to discourage the further influx of the portfolio investment. In this nonorthodox monetary policy, the CBRT did not rely on just one policy rate to fund the financial system. The CBRT used an asymmetric interest rate corridor and various instruments to adjust the daily liquidity without changing the policy rate and created interest rate uncertainty to discourage credit expansion. ${ }^{1}$ During this period, the average funding rate became the critical variable to understand the monetary stance of the CBRT instead of the 1-week repo rate. As shown in Figure 4, the average funding rate and the repo rate diverged sharply in many periods between 2012 and 2018. On the one hand, this monetary policy-mix became somewhat successful in slowing down the rampant current account deficit until 2016. On the other hand,

\footnotetext{
${ }^{1}$ See Kara $(2015,2016)$ for more information about the macroprudential policy mix of the CBRT.
} 
the CBRT has been missing inflation targets every year since 2010. In June 2018, the CBRT officially abandoned the unconventional monetary policy mix, as can be seen in Figure 4.

In August 2018, Turkey faced a severe financial shock due to a currency attack. A rapid government-led credit expansion coupled with an increasing current account deficit eroded the trust in the Turkish Lira and triggered a sharp depreciation. The CBRT quickly increased the policy rate to stop the depreciation of the Turkish Lira and maintained financial stability. However, Turkey experienced an economic recession in the second half of 2018.

\section{Estimation Model}

\subsection{A Two-Stage Regression Framework}

In this paper, we consider a monetary policy response function, which is augmented with the real exchange rate dynamics and time-varying coefficients. However, we first start with a simple linear policy function to elaborate on our framework. Consider the following policy function with forward-looking dynamics (see Taylor, 1993; Clarida et al., 1998): $i_{t}^{*}=\mathrm{r}+$ $\pi_{\mathrm{t}+\mathrm{k}}^{*}+\beta_{1}\left[E\left(\pi_{t+k} \mid \Omega_{t}\right)-\pi_{t+k}^{*}\right]+\beta_{2} E\left(x_{t} \mid \Omega_{t}\right)$, where $i_{t}^{*}$ is the target nominal policy rate, $\pi_{\mathrm{t}+\mathrm{k}}^{*}$ is the target inflation rate, $E\left(\pi_{t+k} \mid \Omega_{t}\right)$ is the $k$ period ahead inflation expectation with the information set $\Omega_{t}$ and $x_{t}$ is the output gap. However, after arranging the terms and setting $r_{t}=$ $i_{t}^{*}-\pi_{\mathrm{t}+\mathrm{k}}^{*}$, we have the econometric policy function with the real rate target: $r_{t}=r+$ $\beta_{1}\left[E\left(\pi_{t+k} \mid \Omega_{t}\right)-\pi_{t+k}^{*}\right]+\beta_{2} x_{t}+\epsilon_{t}$ (see Yazgan and Y1lmazkuday (2007) for the details of the derivation). Finally, adding the exchange rate series and smoothing dynamics for the real rate target in the equation, we represent this function with the following linear Taylor rule equation with time-varying coefficients,

$r_{t}=\alpha_{t}+\rho_{t} r_{t-1}+\beta_{1, t} \tilde{\pi}_{t+k}+\beta_{2, t} x_{t}+\beta_{3, t} e x_{t}+u_{t} \quad \forall t=1, \ldots, T$,

where $T$ is the sample size, $r_{t}$ is the real rate target which is the difference between the nominal policy rate and the inflation target of the CBRT, and $\tilde{\pi}_{t+k}$ is the inflation gap, which is defined as the deviation of the inflation target from 12 months ahead inflation expectations. $x_{t}$ and $e x_{t}$ are defined as the output and the REER gaps, which are the cyclical components of the industrial production index (IPI) and the REER, respectively. Finally, $\rho_{t}$ is the smoothing parameter.

As the literature shows that Equation (1) is subject to the endogeneity problem, estimating Equation (1) using an ordinary or a nonlinear least square procedure is not possible (e.g., Carvalho and Nechio, 2014; Clarida et al., 1998; Kim and Nelson, 2006). Therefore, we use a 2SLS procedure to estimate Equation (1) by taking into account the endogeneity problem. Our 2SLS procedure can be summarized as follows:

1. We regress each of $\tilde{\pi}_{t+k}, x_{t}$ and $e x_{t}$ on the lagged values of these variables by using the equations in (2)-(4):

$$
\begin{aligned}
& \tilde{\pi}_{t+k}=\beta_{0, \tilde{\pi}}+\sum_{j \in S} \beta_{j, \tilde{\pi}} \tilde{\pi}_{t+k-j}+\sum_{j \in S} \theta_{j, \tilde{\pi}} \tilde{x}_{t-j}+\sum_{j \in S} \beta_{j, \tilde{\pi}} e x_{t-j}+\sum_{j \in \frac{S}{\{1\}}} \beta_{j, \tilde{\pi}} r_{t-j}+e_{t, \tilde{\pi}} ; \\
& x_{t}=\beta_{0, x}+\sum_{j \in S} \beta_{j, x} \tilde{\pi}_{t+k-j}+\sum_{j \in S} \theta_{j, x} \tilde{x}_{t-j}+\sum_{j \in S} \phi_{j, x} e x_{t-j}+\sum_{j \in \frac{s}{\{1\}}} \beta_{j, x} r_{t-j}+e_{t, x} \\
& \text { ext }=\beta_{0, e x}+\sum_{j \in S} \beta_{j, e x} \tilde{\pi}_{t+k-j}+\sum_{j \in S} \theta_{j, e x} \tilde{x}_{t-j}+\sum_{j \in S} \phi_{j, e x} e x_{t-j}+\sum_{j \in\{s} \beta_{j, e x} r_{t-j}+e_{t, e x},
\end{aligned}
$$

where $S$ is a set of integers, and we choose $S=\{1, \ldots, 6,9,12\}$ as in Clarida et al. (1998). Note 
that for each equation in (2)-(4), we need to estimate 33 parameters, including the intercept term. Considering the degrees of freedom in each equation, we decide to use a more parsimonious regression method. To achieve this goal, we adopt a penalized regression framework that consists of two steps. In the first step, we employ the conventional Lasso estimation for each equation to determine non-zero coefficients in Equations (2)-(4). After dropping the variables that have zero coefficients in the first stage, we estimate Equations (2)(4) using ordinary least squares (OLS) in the second stage. Belloni et al. (2013) also proposed a similar method.

2. From the first stage of the 2SLS procedure, we obtain the fitted values of $\tilde{\pi}_{t+k}, x_{t}$ and $e x_{t}$ and denote them as $\widehat{\tilde{\pi}}_{t+k}, \widehat{x}_{t}$ and $\widehat{e x}_{t}$. Then, we plug these values into Equation (1) as follows:

$r_{t}=\alpha_{t}+\rho_{t} r_{t-1}+\beta_{t, 1} \widehat{\tilde{\pi}}_{t+k}+\beta_{2, t} \hat{x}_{t}+\beta_{3, t} \widehat{e x}_{t}+u_{t}$,

where we can estimate this regression model with the Flexible Least Square (FLS) method of Kalaba and Tesfatsion (1998).

We can consider this method as a time-varying parameter 2SLS model. Time variation in the policy and smoothing parameters allows us to achieve a flexible policy analysis.

\subsection{Flexible Least Squares}

We devote this section to discuss the details of the FLS algorithm, which follows Kalaba and Tesfatsion (1998). According to Kalaba and Tesfatsion (1998), the FLS method relies on the prior specifications on the measurement equation and the coefficient stability. These specifications can be customized for our analysis as follows:

Prior measurement specification: $r_{t}-Z_{t}^{\top} \beta_{t}=$ error $_{M, t} \approx 0, \forall t=1, \ldots, T$;

Prior dynamic specification: $\beta_{t+1}-\beta_{t}=\operatorname{error}_{C, t} \approx 0, \forall t=1, \ldots, T$,

where $Z_{t}=\left[1, r_{t-1}, \hat{\tilde{\pi}}_{t+k}, \hat{x}_{t}, \widehat{e x}_{t}\right]$ is the vector of the regressors in the second stage and $\beta_{t+1}=$ $\left[\alpha_{t}, \rho_{t}, \beta_{1, t}, \beta_{2, t}, \beta_{3, t}\right]$ is the vector of the coefficients in Equation (5).

In this model, there are two types of error. The first one is the measurement error, error $_{M, t}$, which appears in Equation (6). The second error observed in Equation (7), error $_{C, t}$ is associated with coefficient stability. We can calculate the sum of squared errors for both measurement and coefficient stability errors by using the following equations:

$$
\begin{aligned}
& \operatorname{SSR}_{M}(\beta ; T)=\sum_{t=1}^{T}\left(r_{t}-Z_{t}^{\top} \beta_{t}\right)^{2}, \\
& \operatorname{SSR}_{C}(\beta ; T)=\sum_{t=1}^{T}\left(\beta_{t+1}-\beta_{t}\right)^{\top}\left(\beta_{t+1}-\beta_{t}\right),
\end{aligned}
$$

where $\beta=\left(\beta_{1}, \ldots, \beta_{T}\right)$ and " $\mathrm{T}^{\prime \prime}$ denotes the vector transpose. To obtain the FLS estimator, we can write the objective function as follows:

$$
\begin{aligned}
& C(\beta ; T, \mu)=\operatorname{SSR}_{M}(\beta ; T)+\mu \operatorname{SSR}_{C}(\beta ; T) \\
& C(\beta ; T, \mu)=\sum_{t=1}^{T}\left(r_{t}-Z_{t}^{\top} \beta_{t}\right)^{2}+\mu \sum_{t=1}^{T}\left(\beta_{t+1}-\beta_{t}\right)^{\top}\left(\beta_{t+1}-\beta_{t}\right) .
\end{aligned}
$$

This cost function is a linear combination of the sum of squared errors from the measurement and coefficient equations. Here, the crucial parameter, $\mu \geq 0$, is used to determine the tradeoff between a smooth coefficient or a better model fit. Note that if $\mu=\infty$, the FLS collapse to 
the classical least square problem. Additionally, if $\mu=0$, then the measurement error goes to zero, thus the model perfectly fits the dependent variables. These two conditions indicate that the solution to the FLS algorithm depends on the choice of $\mu$. In this study, we use three different $\mu$ values, which are 1,10 , and 100 .

We can compute the solution for $\beta$ by using a recursive algorithm summarized below:

1. Set $\mu$ as a positive real number;

2. Define $Z(T)=\left[Z_{1}^{\top}, \ldots, Z_{T}^{\top}\right]^{\top}$ as a $T \times 5$ matrix, $\beta(T)=\left[\beta_{t}^{\top}, \ldots \beta_{T}^{\top}\right]$ as a $5 T \times 1$ vector and $r(T)=\left(r_{1}, \ldots, r_{T}\right)^{\top}$ as a $T \times 1$ vector;

3. The cost function for the estimation of the vector $\beta(T), C(\beta(T) ; T, \mu)$ can be written in matrix notation as:

$C(\beta(T) ; T, \mu)=\beta(T)^{\top} A(\mu, T) \beta(T)-2 \beta(T)^{\top} G(T) r(T)+r(T)^{\top} r(T)$, where

$$
\begin{aligned}
& G(T)=\left[\begin{array}{lll}
Z_{1} & & 0 \\
& \ddots & \\
0 & & Z_{T}
\end{array}\right] ; \\
& A(\mu, T)=\left[\begin{array}{llllll}
A_{1}(\mu) & -\mu I & 0 & \ldots & \ldots & 0 \\
-\mu I & A_{2}(\mu) & -\mu I & & & . \\
0 & -\mu I & . & & & . \\
\cdot & & & . & & 0 \\
\cdot & & & & . & -\mu I \\
0 & \ldots & \ldots & 0 & -\mu I & A_{T}(\mu)
\end{array}\right] ; A_{t}(\mu)=\left(\begin{array}{lll}
Z_{1} Z_{1}^{\top}+\mu I & \text { if } t=1 ; \\
Z_{t} Z_{t}^{\top}+2 \mu I & \text { if } t \neq 1, T ; \\
Z_{T} Z_{T}^{\top}+\mu I & \text { if } t=T .
\end{array}\right.
\end{aligned}
$$

4. Minimizing $C(\beta(T) ; T, \mu)$ with respect to $\beta(T)$, we get the FLS estimator as $\beta^{F L S}(\mu ; T)=A(\mu, T)^{-1} G(T) r(T)$. Notice that $\beta^{F L S}(\mu ; T)$ can be unstacked to obtain the timevarying coefficients for each regressor. We define the coefficient estimate of the $\mathrm{k}^{\text {th }}$ regressor at time $t$ as $\beta_{t, k}^{F L S}$.

Furthermore, we can obtain the variance of the estimated coefficients with the following equation: $\operatorname{var}\left(\beta^{\mathrm{FLS}}(\mu ; \mathrm{T})\right)=\hat{\sigma}^{2} \mathrm{~A}(\mu, \mathrm{T})^{-1} \mathrm{G}(\mathrm{T}) \mathrm{G}(\mathrm{T})^{\prime} \mathrm{A}(\mu, \mathrm{T})^{-1}$, where $\hat{\sigma}^{2}$ is a consistent estimator of the residual variance. Similarly, we can unstack $\operatorname{var}\left(\beta^{\mathrm{FLS}}(\mu ; \mathrm{T})\right)$ and take the square root of each element to obtain the standard error of the time-varying coefficients, denoted as $\operatorname{std}\left(\beta_{t, k}^{F L S}\right)$. Using these coefficient estimates and standard errors, we can compute the confidence bands for the time-varying coefficients. Suppose that the significance level is given as $\eta$. Then, the confidence interval for the coefficient estimate of the $k^{\text {th }}$ regressor at time $t$ is written as $\left[\beta_{t, k}^{F L S}-s t d\left(\beta_{t, k}^{F L S}\right) \mathrm{t}_{\mathrm{T}-\mathrm{k}}(1-\eta), \beta_{t, k}^{F L S}+s t d\left(\beta_{t, k}^{F L S}\right) \mathrm{t}_{\mathrm{T}-\mathrm{k}}(1-\eta)\right]$, where $\mathrm{t}_{\mathrm{T}-\mathrm{k}}(1-\eta)$ is the $(1-\eta)^{\mathrm{th}}$ quantile of the student $\mathrm{t}$ distribution with $T-k$ degrees of freedom. Further details of the procedure can be found in Kalaba and Tesfatsion (1998); thus, we skip them for brevity.

\section{Data}

As the inflation gap, we use the difference between the inflation target and 12 months ahead inflation expectations ${ }^{2}$ retrieved from the CBRT's survey of expectation. For the real rate

\footnotetext{
${ }^{2}$ Bulut (2016) analyses whether the CBRT takes into account of 12 months ahead inflation expectations or 24 months inflation expectations when conducting monetary policy and shows that the CBRT uses 12 months inflation expectations for determining interest rates.
} 
target, we use the difference between the policy rate of the CBRT and the inflation target of the CBRT. Since the start of the inflation targeting, the CBRT uses various policy rates. Between 2002M02 and 2010M05, the CBRT employed the overnight interest rate on borrowing as the policy rate. On 18.05.2010, the CBRT declared that the 1-week repo rate is the new policy rate, but shortly after this decision, the CBRT adopted a heterodox monetary policy in 2011 and used the weighted average funding rate as the effective policy rate. Using the different policy rates for the different periods may not be suitable in some cases, so we use the overnight TRLIBOR rate as the nominal interest rate in our model, given that effective policy rate directly influences the overnight TRLIBOR as seen in Figure $4^{3}$. We obtain data for the interest rates from the Turkey Data Monitor. For the inflation target, we need to obtain the 12 months ahead inflation target of the CBRT. However, the CBRT only releases the fixed year-end inflation targets. By following Yazgan and Yilmazkuday (2007), we construct the variable inflation targets for each month from the fixed inflation targets. ${ }^{4}$ For the output gap, we detrended the seasonally adjusted industrial production index, which is obtained from the Turkish Statistical Institute by the Hodrick-Prescott (HP) filter. Finally, we detrended the CPIbased effective real interest rate derived by the CBRT by the HP filter for the REER gap.

\section{Empirical Results}

In this section, we present the evolution of the Taylor rule equation's coefficients estimated with the flexible 2SLS. We also test whether the instruments used in the two-stage procedure are valid. Our estimation covers the explicit inflation targeting period, which is between 2006M01 and 2019M03. We use three different $\mu$ in the estimation of our flexible 2SLS methodology.

First, we employ the over-identification restrictions test by following the seminal articles of Sargan (1958) and Hansen (1982). This test simply checks whether the instruments used in the two-stage procedure are valid. The validity criterion is satisfied if the instruments are independent of the residuals of the second-stage regression. This test requires an additional regression, which includes the residuals of the second stage as the dependent variable and the instruments as explanatory variables. We can calculate the test statistic for the Sargan-Hansen test as $T \times R^{2}$ where $R^{2}$ is the goodness of fit measure in this new regression. Under the null hypothesis, the overidentification restrictions on the instruments are valid, the test statistic is asymptotically $\chi^{2}\left(m-k_{z}\right)$ distributed, where $m$ is the number of endogenous regressors and $k_{z}$ is the included instruments in the first stage. In our case, $m-k_{z}=18$ and the null hypothesis can be rejected if the test statistic is higher than $\% 95$ quantile of $\chi^{2}\left(m-k_{z}\right)$. We present the test results in Table 1 . According to these results, we can claim that the instruments used in the first stage of our estimation procedure are independent of the residuals of the second stage and thus are valid instruments. This conclusion is apparent for all values of the parameter $\mu$. Notice that, the critical value of the test statistic is the same for all $\mu$, since we utilize the same instruments from the first stage regression.

Table 2 presents the OLS results of the first stage regressions after the Lasso estimation for the inflation, output, and REER gaps. Without utilizing a Lasso regression, we need to estimate 33

\footnotetext{
${ }^{3}$ Furthermore, TRLIBOR has a good forecasting performance of monetary policy expectations in short horizons (Akçelik and Talaslı, 2020).

${ }^{4}$ As Yazgan and Yilmazkuday (2007), we obtain 12 months ahead inflation targets by assuming inflation targets fall the first month of each year and fill out the missing inflation targets by using a linear interpolation between inflation targets.
} 
parameters for each equation. Thanks to the Lasso regression, we only need to estimate 17 parameters for the output gap, 15 parameters for the inflation gap, and 18 parameters for the REER gap equations. This procedure simply removes the redundant regressors, decreases the estimation complexity, and increases the degrees of freedom.

Next, we present the second stage results of our flexible 2SLS procedure. Figure 7 shows the evaluation of the Taylor rule equation's coefficients. We demonstrate in Figure 7 that the evaluation of coefficients is much smoother and plausible when using $\mu=100$ instead of $\mu=$ 10 or $\mu=1$. However, using different $\mu$ parameters does not change the general behavior of the coefficients.

For the period until the global financial crisis, we see that the smoothing parameter $\rho_{t}$ fluctuates around one, and the inflation gap fluctuates around zero. These results indicate that the CBRT was just following the trend and was not acting proactively during this period by adjusting the interest rate according to the inflation gap. This issue may be one of the reasons why the CBRT missed the inflation targets in 2006, 2007, and 2008 as shown in Figure 2. The coefficient of the output gap is slightly positive around 0.15 , which indicates that the CBRT followed a counter-cyclical monetary policy until the crisis. When the Turkish economy accelerates (slows down), the CBRT increases (decreases) the policy rate. At the start of the period, the REER gap is negative, but it slowly increases to zero. Even though the CBRT was supportive of the exchange rate initially, this policy slowly phased out as the REER became highly overvalued. After the global financial crisis, the importance of the smoothing parameter declines until 2013 and then increases back to 0.8 afterward. The increasing impact of the smoothing parameter after 2013 may be related to the surge of the inflation rate in the last few years. According to $\mu=100$, the importance of the inflation gap in the monetary policy function of the CBRT was increasing steadily and stabilized around 0.4 after 2015. For $\mu=1$ and $\mu=10$, there are some extreme movements both for the inflation gap and the smoothing parameter. Even though the general trend of $\mu=1$ and $\mu=10$ is in line with $\mu=100$.

Despite the results, which indicate that the CBRT started considering the inflation gap after the crisis, the CBRT seems to abandon the counter-cyclical monetary policy as the coefficient of the output gap rapidly declines to zero between 2010 and 2011. Soybilgen et al. (2019) also present a similar finding for 2009-2011 and argue that this monetary policy mix may explain the very high growth rates that occurred in 2010 and 2011. Results of $\mu=1$ and $\mu=10$ show that after 2011, at least until 2014, the CBRT again adopted a firm counter-cyclical monetary policy. For $\mu=100$, this effect is much milder. Additionally, the coefficient of the output gap declines after 2014. We witness another increase in the output gap's coefficient starting from 2018 as the CBRT tried to reduce the current account deficit to prevent a crisis.

If we consider the REER gap after the global financial crisis, the CBRT seems to prevent the depreciation of the Turkish Lira by increasing the interest rate whenever the REER starts to decline rapidly both in 2011 and 2012 and the period after 2015.

When taking account of all results, the 2SLS procedure with $\mu=100$ seems to produce the most plausible and robust results. For the more detailed analysis, we also present coefficients of the 2SLS procedure with the confidence intervals for $\mu=100$ in Figure 8. The confidence bands seem to be well-behaved in Figure 8. For instance, the negative coefficients for the output gap and the inflation gap are insignificant. Similarly, the positive coefficients for the REER gap are also mostly insignificant. It presents a more well-behaved monetary policy function when we add the confidence bands. 
To further show how our FLS model with $\mu=100$ performs compared to other models in the literature, we also estimate Equation (5) with a recursive least square model (RLS), an OLS with 60 months rolling window ${ }^{5}$ (RW), and an OLS using the full sample (OLS). We lost more information than the FLS when estimating the RLS and RW at the start of the sample period compared to FLS. For the smoothing parameter, the RLS produces stable estimates just below 1, similar to the OLS case. Even though the smoothing term coefficient of the RW is similar to the RLS until 2013. After this period, the coefficient of the smoothing term decreased to 0.8 and fluctuated around this value. For the inflation gap, both the FLS and RW have the upward trending estimates, even though the RW produces more hectic coefficients than the FLS. However, the RLS produces estimates much closer to OLS. For the output gap, FLS, RW, and RLS convey similar stories. The output gap has a high and positive coefficient initially, but the importance of the output gap in the monetary policy function decreases after 2011.

Furthermore, the OLS cannot capture such changes in the monetary policy function of the CBRT. The estimation of the REER gap is where the FLS methodology shines. The coefficient of the REER gap estimated by the OLS is -0.05 . The RLS also produces similar estimates for the REER gap for most parts of the sample period. Additionally, the RW is slightly better at capturing the changes in the monetary policy. However, the RW puts too much weight on past information and updates the coefficient very slowly. We are quite confident that the CBRT takes account of the exchange rate when conducting monetary policy, especially in times of rapid deceleration of the Turkish Lira. Only the FLS captures this successfully.

\section{Conclusion}

Many studies analyze the monetary policy function of the CBRT. However, none of them uses a time-varying endogenous model to estimate the Taylor rule equation of the CBRT, even though the Turkish economy has undergone various structural transformations in the last 15 years. In this study, we propose a novel 2SLS methodology using Lasso estimation in the first stage and the FLS estimation in the second stage. The FLS estimation takes into account both the endogeneity problem and time-varying nature of the monetary policy function of the CBRT. Our results show that the CBRT takes account of the exchange rate when conducting monetary policy and mostly supports the Turkish Lira during the inflation-targeting period. Especially during the rapid depreciation of the Turkish Lira, the CBRT put increasing weight on the REER gap in its monetary policy function. We also show that the CBRT adopted a firm countercyclical monetary policy until the global financial crisis. After the crisis, the importance of the output gap decreases in the monetary policy mix.

Furthermore, our results indicate that the CBRT did not put too much emphasis on the inflation gap until 2011 and mostly focused on smoothing the monetary policy function by considering the last period's real target rate. However, the inflation gap becomes increasingly crucial for the CBRT after 2012.

Finally, we compare our FLS Taylor equation to a time-invariant Taylor equation and Taylor models estimated by RW and RLS, and we clearly show that ignoring the time-variant nature of monetary policy equations would yield misleading results. Furthermore, the FLS presents the changes in the monetary policy of the CBRT better than the RW and RLS. Therefore, future studies should pay more attention to parameter changes in the Taylor rules.

\footnotetext{
${ }^{5}$ We also estimate with a 48 months rolling window. Results from a 48 months rolling window are similar to a 60 months rolling window estimation but much more erratic.
} 


\section{References}

Akçelik, F., \& Talasl1, A. (2020). Market-based monetary policy expectations for Turkey. Central Bank Review, 20(1), 9-19.

Aklan, N. A., \& Nargelecekenler, M. (2008). Taylor rule in practice: Evidence from Turkey. International Advances in Economic Research, 14(2), 156-166.

Belloni, A., V. Chernozhukov, et al. (2013). Least squares after model selection in highdimensional sparse models. Bernoulli 19(2), 521-547.

Bulut, U. (2016). How far ahead does the Central Bank of the Republic of Turkey look?. Journal of Central Banking Theory and Practice, 5(1), 99-111.

Carvalho, C. and F. Nechio (2014). Do people understand monetary policy? Journal of Monetary Economics 66, 108-123.

Civcir, I., \& Akçağlayan, A. (2010). Inflation targeting and the exchange rate: Does it matter in Turkey?. Journal of Policy Modeling, 32(3), 339-354.

Çiçek, S. (2013). Asymmetry and non-linearity in monetary policy of a small open economy: evidence from Taylor rule. International Research Journal of Finance and Economics, 107, 140-153.

Clarida, R., J. Galı, and M. Gertler (1998). Monetary policy rules in practice: Some international evidence. European Economic Review 42(6), 1033-1067.

Erdem, E., Bulut, U., \& Kocak, E. (2017). Have financial stability concerns changed the priority of the Central Bank of the Republic of Turkey? Studies in Business and Economics, 12(2), 35-45.

Gozgor, G. (2012). Inflation targeting and monetary policy rules: further evidence from the case of Turkey. Journal of Applied Finance and Banking, 2(5), 127.

Güney, P. Ö. (2016). Does the central bank directly respond to output and inflation uncertainties in Turkey?. Central Bank Review, 16(2), 53-57.

Hansen, L. P. (1982). Large sample properties of generalized method of moments estimators. Econometrica: Journal of the Econometric Society, 1029-1054.

Kalaba, R. and L. Tesfatsion (1988). The flexible least squares approach to time-varying linear regression. Journal of Economic Dynamics and Control 12(1), 43-48.

Kara, H. (2008). Turkish Experience with Implicit Inflation Targeting. Central Bank Review, $8(1), 1-16$.

Kara, A. H. (2015). Interest Rate Corridor and the Monetary Policy Stance (No. 1513). Research Notes in Economics No. 2015-13, Central Bank of the Republic of Turkey. 
Kara, H. (2016). Turkey's experience with macroprudential policy. BIS Papers No. 86, 123140.

Kayhan, S., T. Bayat, and A. Koçyiğit (2013). Enflasyon hedeflemesi rejiminde öğrenme süreci ve asimetri: Markov switching yaklaşımı. Eskişehir Osmangazi Üniversitesi İktisadi ve İdari Bilimler Dergisi 8(1), 191-212.

Kim, C.-J. and C. R. Nelson (2006). Estimation of a forward-looking monetary policy rule: A time-varying parameter model using ex-post data. Journal of Monetary Economics 53(8), 1949-1966.

King, M. et al. (1996). How should central banks reduce inflation? Conceptual issues. Economic Review-Federal Reserve Bank of Kansas City 81, 25-52.

Brada, J. C., \& Kutan, A. M. (1999). The persistence of moderate inflation in the Czech Republic. Post-Soviet Geography and Economics, 40(2), 121-134.

Kuttner, K. N. (2004). The role of policy rules in inflation targeting. Review-federal Reserve Bank of Saint Louis, 86(4), 89-112.

Mohanty, M. S. and M. Klau (2005). Monetary policy rules in emerging market economies: Issues and evidence. In R. J. Langhammer and L. V. de Souza (Eds.), Monetary Policy and Macroeconomic Stabilization in Latin America, pp. 205-245. Berlin, Heidelberg: Springer.

Sargan, J. D. (1958). The estimation of economic relationships using instrumental variables. Econometrica: Journal of the Econometric Society, 393-415.

Soybilgen, B., B. A. Eroglu, and H. Yener (2019). Taylor rule for Turkey under multiple structural breaks. In Ç. Yurtseven and M. Tekce (Eds.), Current Issues in Turkish Economy: Problems and Policy Suggestions, pp. 11-24. Bern, Switzerland: Peter Lang.

Taylor, J. B. (1993). Discretion versus policy rules in practice. In the Carnegie-Rochester conference series on public policy, Volume 39, pp. 195-214. Elsevier.

Taylor, J. B. (2000). Using monetary policy rules in emerging market economies. Revised Paper presented at 75th Anniversary Conference, "Stabilization and Monetary Policy: The International Experience.", Bank of Mexico.

Taylor, J. B. (2001). The Role of the Exchange Rate in Monetary-Policy Rules. American Economic Review, 91(2), 263-267.

Yazgan, E. and H. Yilmazkuday (2007). Monetary policy rules in practice: Evidence from Turkey and Israel. Applied Financial Economics 17(1), 1-8.

Yüksel, E., K. Metin-Ozcan, and O. Hatipoglu (2013). A survey on time-varying parameter Taylor rule: A model modified with interest rate pass-through. Economic Systems 37 (1), 122-134. 
Appendix: Tables and Figures

Table 1: The Results of the Over-identification Restrictions Test

\begin{tabular}{|c|c|c|c|}
\hline$\mu$ & Test Statistic & Critical Value $\left(\chi^{2}(18)\right)$ & $\mathrm{p}$-value \\
\hline 1 & 11.361 & & 0.969 \\
\hline 10 & 15.463 & \multirow{3}{*}{33.924} & 0.842 \\
\hline 100 & 24.731 & & 0.310 \\
\hline
\end{tabular}

Table 2: OLS Results of the First Stage Regressions after Lasso Estimation

\begin{tabular}{|l|c|c|c|}
\hline Variables & $\begin{array}{c}x_{t} \\
\text { Coefficient }\end{array}$ & $\begin{array}{c}\tilde{\pi}_{t} \\
\text { Coefficients }\end{array}$ & $\begin{array}{c}e x_{t} \\
\text { Coefficients }\end{array}$ \\
\hline Intercept & 0.010 & 0.030 & -0.287 \\
\hline$r_{t-2}$ & - & - & -0.031 \\
\hline$r_{t-3}$ & - & - & - \\
\hline$r_{t-4}$ & - & - & - \\
\hline$r_{t-5}$ & 0.135 & - & - \\
\hline$r_{t-6}$ & - & -0.005 & - \\
\hline$r_{t-9}$ & - & - & - \\
\hline$r_{t-12}$ & -0.129 & 0.001 & 0.048 \\
\hline$x_{t-1}$ & 0.508 & 0.011 & - \\
\hline$\tilde{\pi}_{t-1}$ & -0.105 & 1.150 & 0.247 \\
\hline$e x_{t-1}$ & 0.065 & -0.036 & 1.006 \\
\hline$x_{t-2}$ & 0.272 & - & 0.039 \\
\hline$\tilde{\pi}_{t-2}$ & -0.052 & - & - \\
\hline$e x_{t-2}$ & 0.009 & 0.005 & -0.422 \\
\hline$x_{t-3}$ & 0.104 & - & 0.038 \\
\hline$\tilde{\pi}_{t-3}$ & - & -0.141 & - \\
\hline$e x_{t-3}$ & - & 0.022 & 0.243 \\
\hline$x_{t-4}$ & - & - & - \\
\hline$\tilde{\pi}_{t-4}$ & - & - & - \\
\hline$e x_{t-4}$ & - & - & -0.160 \\
\hline$x_{t-5}$ & -0.031 & -0.001 & -0.016 \\
\hline$\tilde{\pi}_{t-5}$ & - & - & - \\
\hline$e x_{t-5}$ & -0.024 & - & - \\
\hline$x_{t-6}$ & -0.105 & - & - \\
\hline$\tilde{\pi}_{t-6}$ & - & - & 0.020 \\
\hline$e x_{t-6}$ & - & - & 0.034 \\
\hline$x_{t-9}$ & - & - & -0.116 \\
\hline$\tilde{\pi}_{t-9}$ & -0.582 & -0.001 & -0.080 \\
\hline$e x_{t-9}$ & 0.178 & -0.011 & - \\
\hline$x_{t-12}$ & - & -0.001 & -0.131 \\
\hline$\tilde{\pi}_{t-12}$ & & & \\
\hline$e x_{t-12}$ & -084 & -215 \\
\hline & - & - & - \\
\hline
\end{tabular}


Figure 1: Year over Year Consumer Price Index Inflation (200M01-2005M12, 2006M01 2019M03)

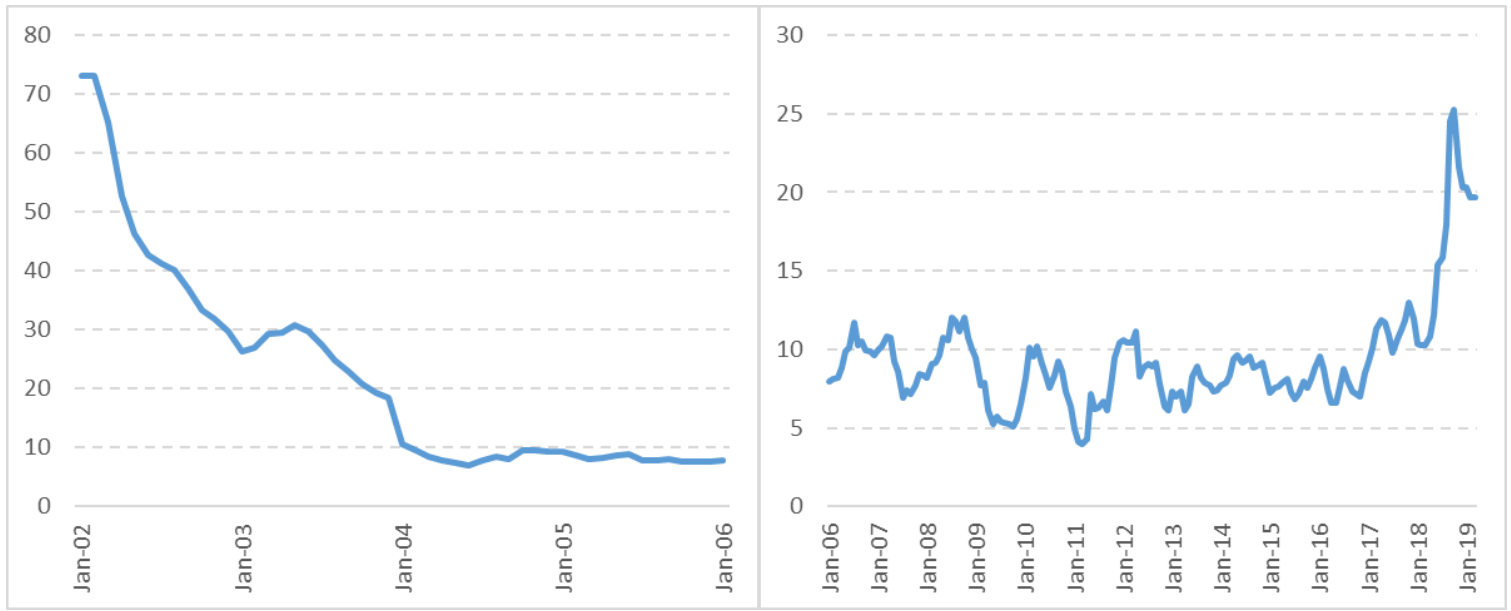

Figure 2: Annual Inflation Targets and Realized Inflation (2002-2019)

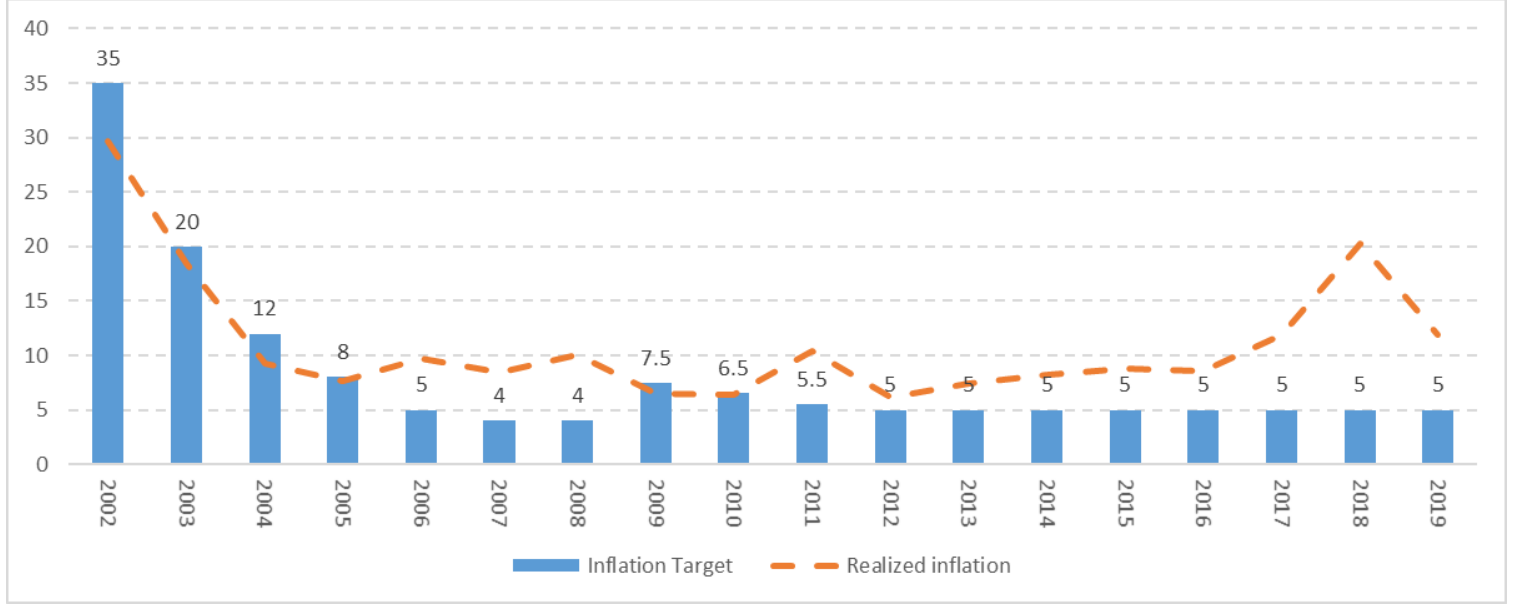

Figure 3: Real Interest Rate, 12 Months Ahead Expected Inflation, and 2 Year Benchmark Interest Rate (200M01-2005M12, 2006M01-2019M03)

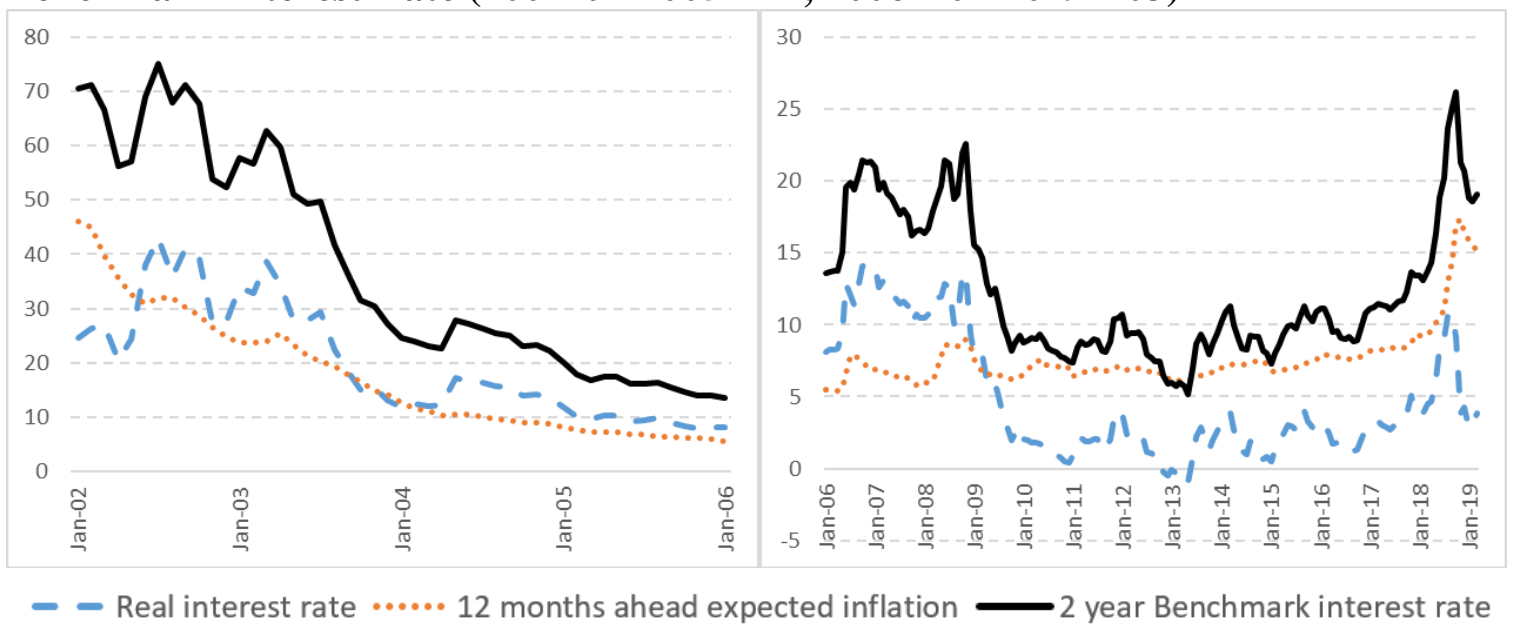


Figure 4: Official Policy Rate, Average Funding Rate, and Overnight TRLIBOR (2002M08-2010M12, 2011M01-2019M03)

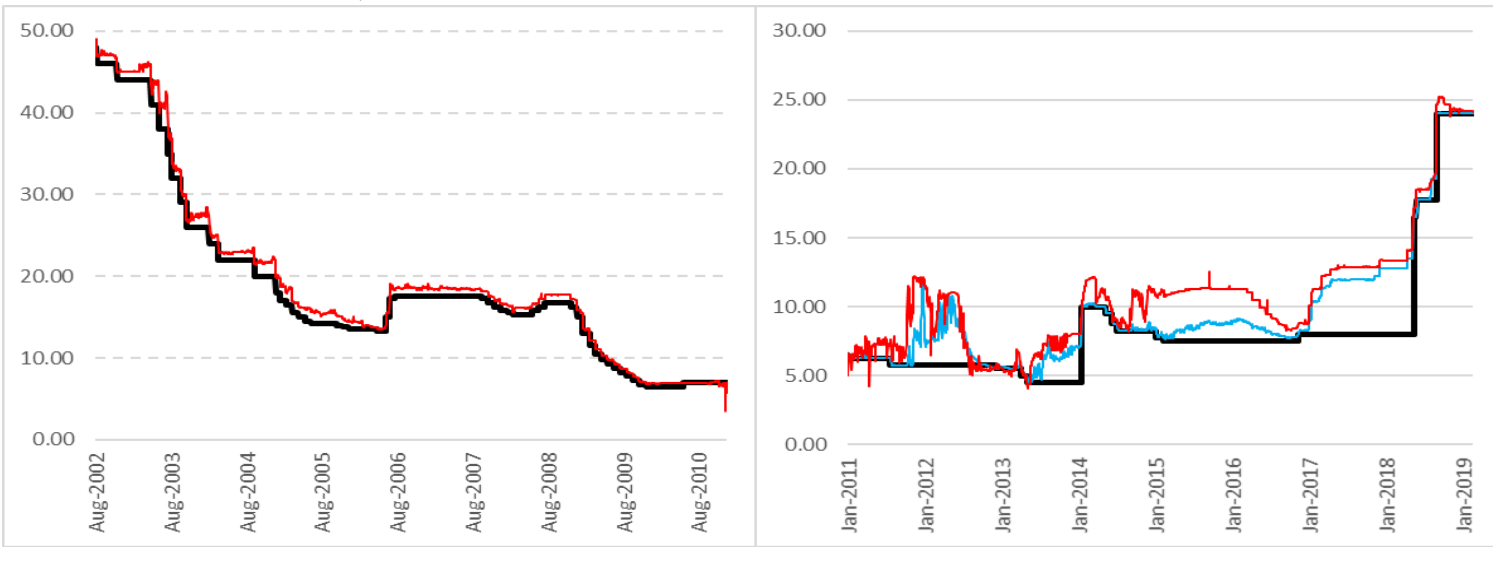

- Official Policy Rate _ _ Average Funding Rate —o/N TRLIBOR

Figure 5: 12 Months Cumulative Current Account Balance and Reel Effective Exchange Rate (2002M01-2019M03)

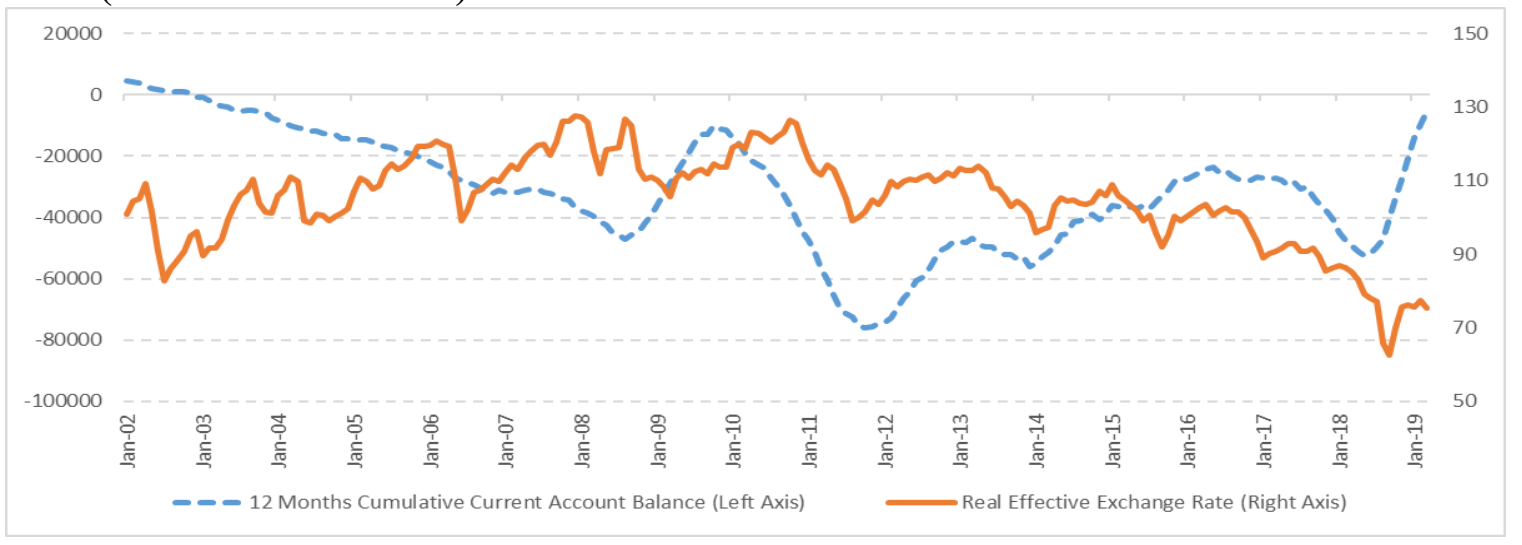

Figure 6: Year over Year Industrial Production Index (2002M01-2019M03)

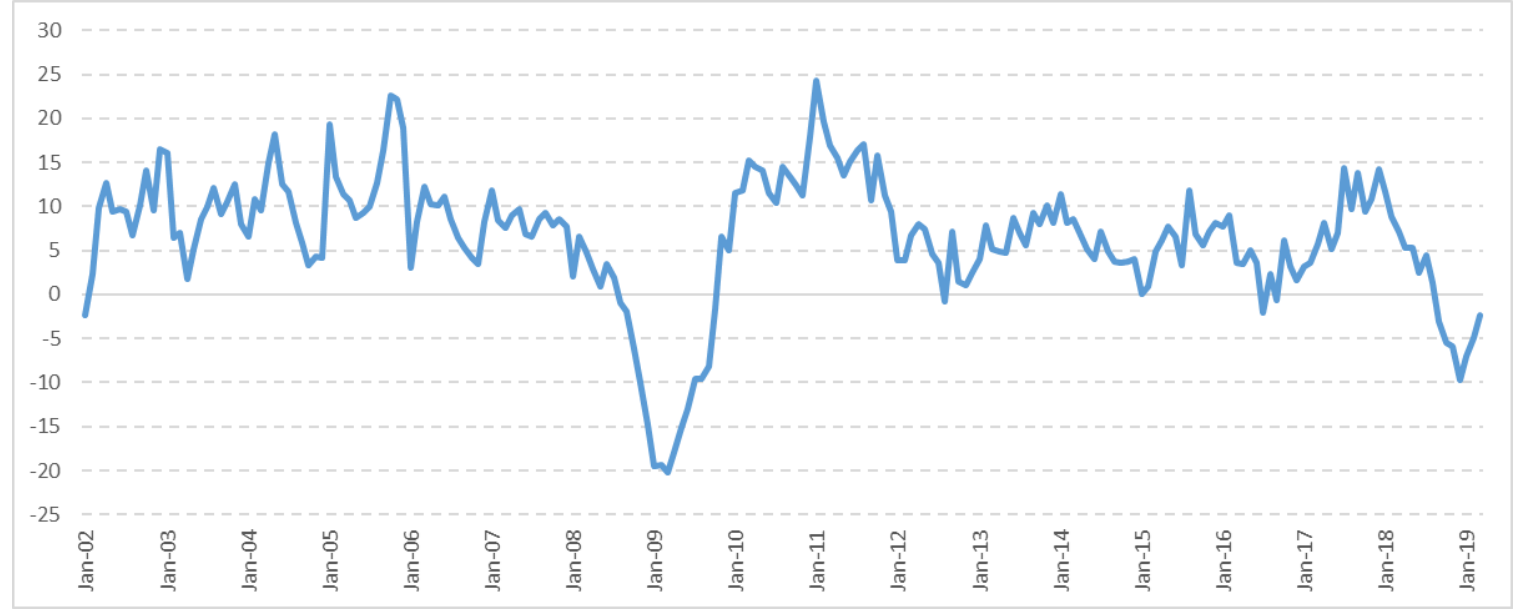


Figure 7: Evaluation of the Flexible 2SLS Coefficients According to Several $\mu$ Parameters

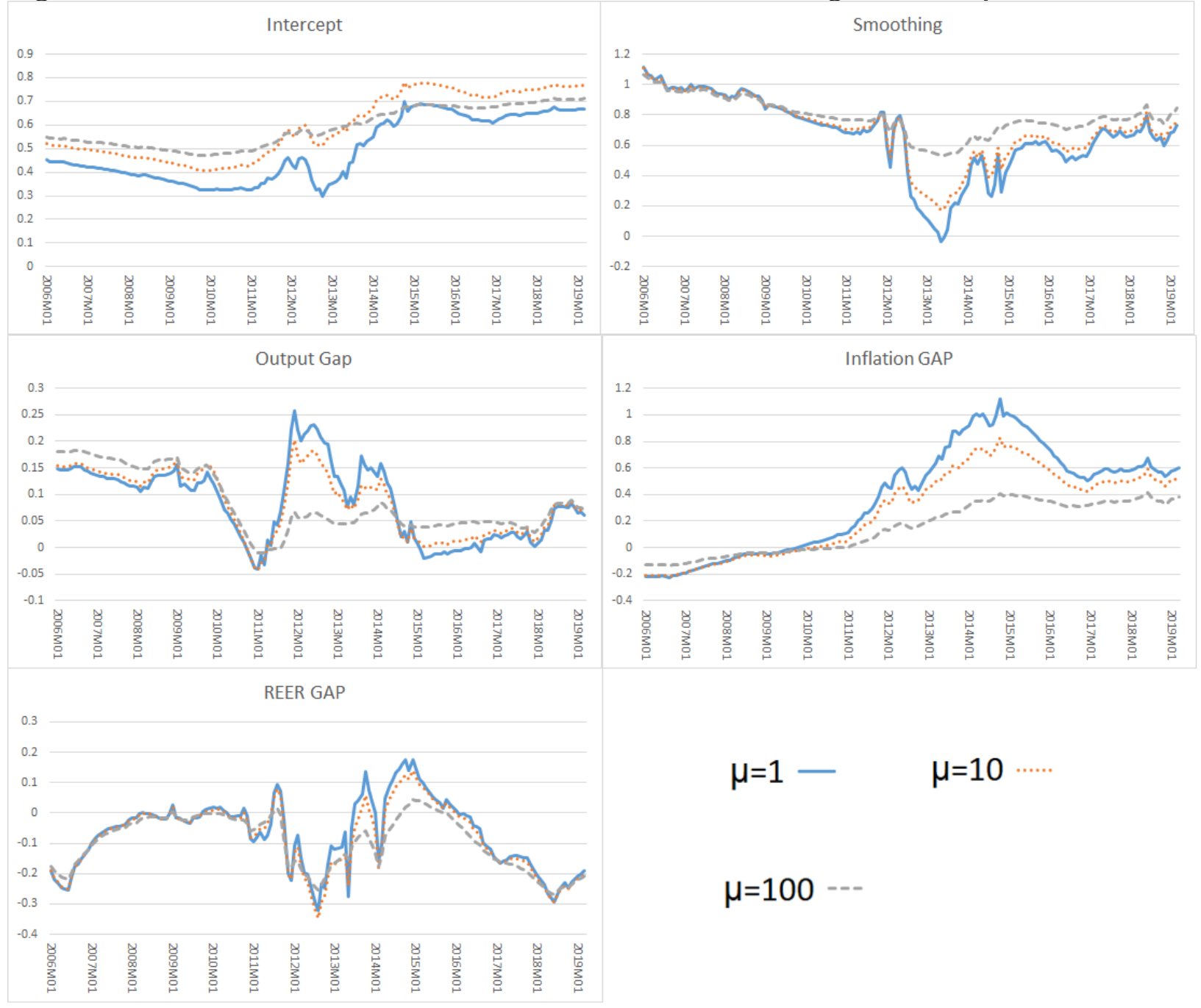


Figure 8: Evaluation of the Flexible 2SLS Coefficients with confidence bands $(\boldsymbol{\mu}=100)$

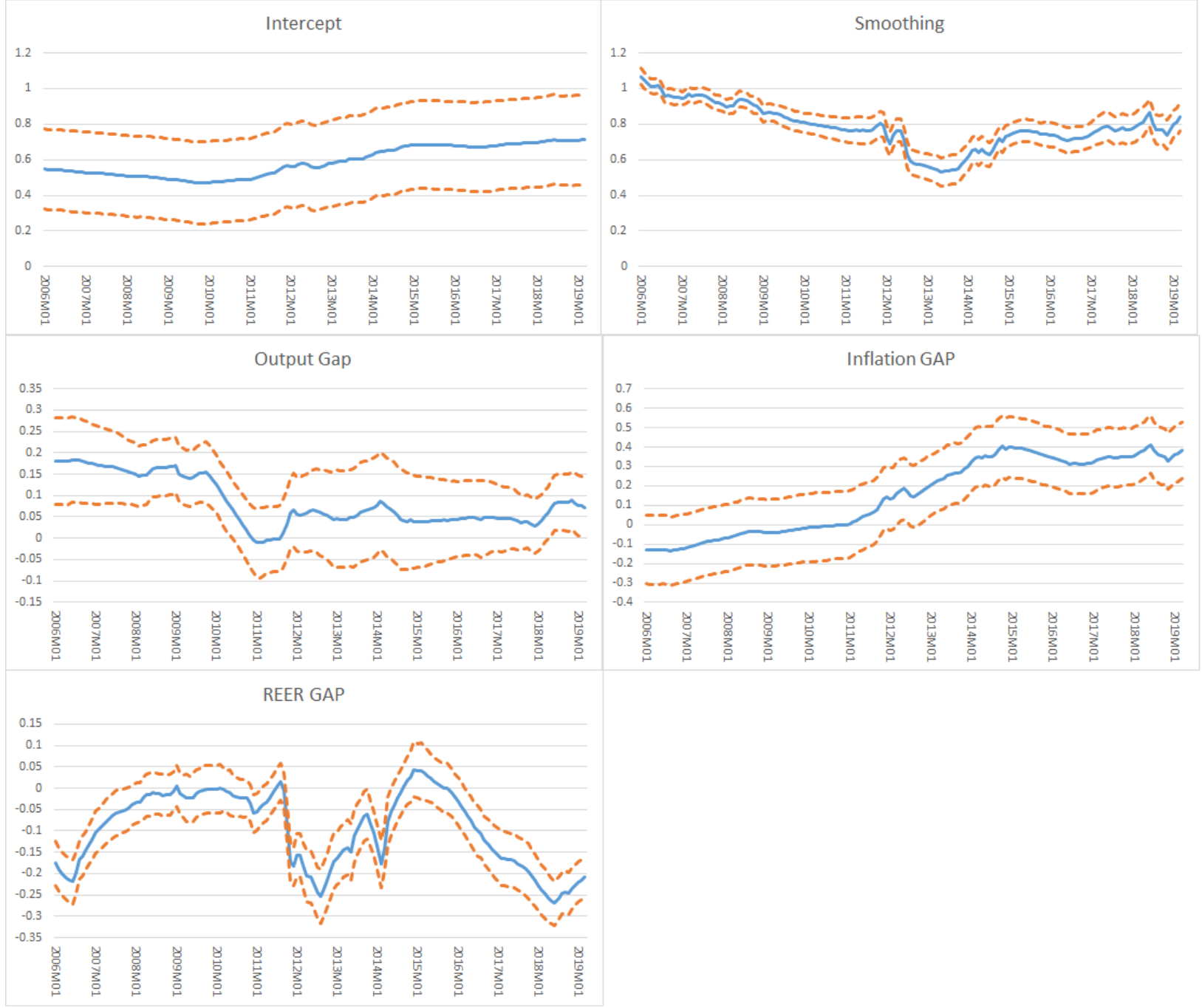


Figure 9: Evaluation of the Flexible 2SLS Coefficients (FLS), the Recursive 2SLS Coefficients (RLS), the 2SLS Coefficients with rolling estimation window (RW), and time-invariant 2SLS Coefficients (OLS)

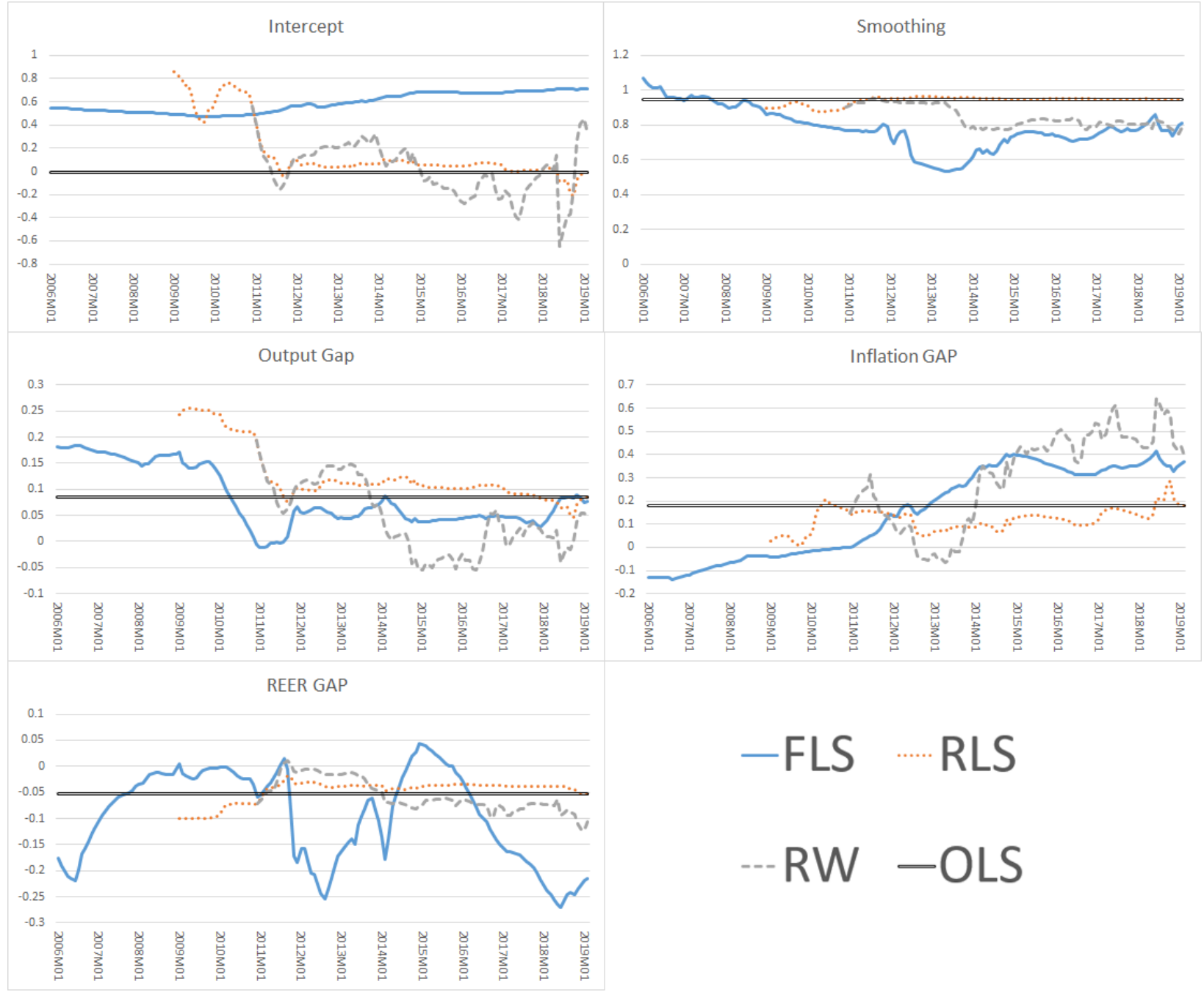

